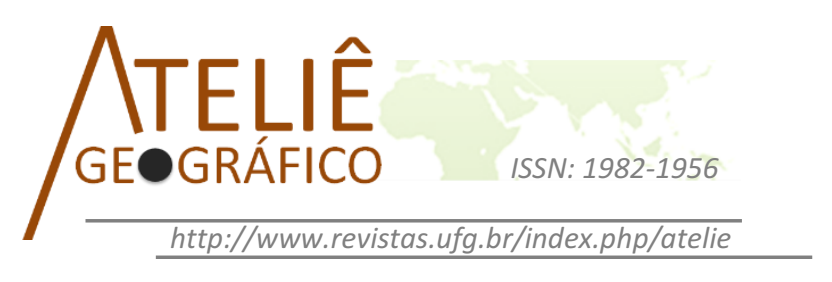

\title{
Erosividade e erodibilidade ao longo de dutovia cortando os estados de Minas Gerais e Goiás - Brasil
}

\author{
Erosivity and erodibility along pipeline cutting the states of \\ Minas Gerais and Goiás - Brazil \\ Erosividad y erodibilidad a lo largo de las tuberías que \\ cortan los estados de Minas Gerais y Goiás - Brasil
}

\author{
Diego Tarley Ferreira Nascimento \\ Universidade Estadual de Goiás \\ diego.tarley@gmail.com
}

Patrícia de Araújo Romão

Universidade Federal de Goiás

patrícia_romao@ufg.br

Maurício Martines Sales

Universidade Federal de Goiás

sales.mauricio@gmail.com

\begin{abstract}
Resumo
Apresenta-se o mapeamento da erosividade e da erodibilidade ao longo da dutovia OSBRA, que corta vários municípios de Minas Gerais e Goiás. Para o mapeamento da erosividade, foram calculados os índices de erosividade de cada estação meteorológicas nas proximidades da área estudada. Para o mapeamento da erodibilidade, foram agrupadas categorias de solos com comportamentos semelhantes quanto à resistência a processos erosivos e posteriormente foi classificada sua suscetibilidade erosiva. Com base nos mapeamentos da erosividade e da erodibilidade foi possível identificar áreas com maior suscetibilidade a processos erosivos. Levantamento de 85 pontos de erosão, cadastrados em campo, foram confrontados com os mapas de erodibilidade e erosividade, resultando em uma grande coerência entre previsão e ocorrências em campo. $\mathrm{O}$ mapeamento apresentado poderá ser usado como critério de decisão sobre qual área deve ter maior monitoramento do que outras, visando a segurança da faixa do duto e de fazendas vizinhas.
\end{abstract}

Palavras-Chave: Erosividade, Erodibilidade, Processos Erosivos. 


\begin{abstract}
This paper presents the erosivity and erodibility mapping along the pipeline OSBRA, which cut the states of Minas Gerais and Goiás. For mapping the erosivity, the erosivity indices were calculated to each weather station near the studied area. To map the erodibility, soils were grouped in classes considering similar resistance to erosion processes, and their erosive susceptibility were subsequently classified. Based on the erosivity and erodibility mappings, areas with greater susceptibility to erosion processes were identified. A collection of 85 points of erosions, registered on the field, were compared with the maps of erodibility and erosivity and resulted in a good agreement between predictions and events in the field. The presented mapping can be used as a decision criterion on which area should have a more intensive monitoring than others, seeking the safety of the pipeline and neighboring farms.
\end{abstract}

Keywords: Erosivity, Erodibility, Erosion processes.

\begin{abstract}
Resumen
Se presenta el mapeo de la erosividad y de la erodibilidad a lo largo de la tubería OSBRA, que corta varios municipios de Minas Gerais y de Goiás. Para mapear la erosividad se calcularon los índices de erosividad de cada estación meteorológica, en las proximidades del área observada. Para mapear la erodibilidad se agruparon categorías de suelos similares, en cuanto a su resistencia a los procesos erosivos. Posteriormente, se clasificó su susceptibilidad erosiva. Considerando los mapeos de erosividad y erodibilidad, se identificaron áreas más susceptibles que otras a los procesos erosivos. Observaciones levantadas a partir de 85 puntos de erosión registrados en campo, confrontadas con los mapas de erodibilidad y erosividad, mostraron coherencia entre la previsión y los datos de campo. El mapeo presentado puede utilizarse para definir cuáles son las áreas que requieren más control y vigilancia, teniendo en cuenta la seguridad de la zona a lo largo de las tuberías, así como la de las haciendas vecinas.
\end{abstract}

Palabras Clave: Erosividad, Erodibilidad, Mecanismo de erosión.

\title{
Introdução
}

A erosão hídrica pode ser considerada um agente modelador da paisagem, compreendendo a desagregação e o transporte de partículas do solo (BERTONI; LOMBARDI NETO, 2010), com posterior deposição. Apesar de ocorrer naturalmente, esse processo geológico pode ser intensificado e acelerado pelas atividades antrópicas, sobretudo no que concerne às mudanças na cobertura e aos usos intensivos do solo.

No caso das regiões tropicais, nas quais se inserem a área de estudos, destacamse as erosões hídricas laminares, associadas à perda de solo dos horizontes superficiais, e as lineares, que, em geral, culminam em feições como sulcos, ravinas ou, até mesmo, voçorocas. Dentre os fatores que promovem a erosão nas regiões intertropicais, destacam-se o impacto da água da chuva (impacto de gotas e alteração do teor de umidade) e a posterior ação do escoamento superficial. A ação da água da chuva pode 
ser qualificada ou quantificada pela sua erosividade, bem como a resistência do material a esse processo erosivo, pela erodibilidade desse material.

As erosões hídricas, principalmente as aceleradas, provocam uma gama de impactos. A perda da camada superficial, por exemplo, corresponde à diminuição da profundidade das camadas que, além de diminuir a capacidade produtiva do solo (OLIVEIRA; WENDLAND; NEARING, 2012; BERTOL et al., 2007), pode ser responsável, no caso de obras enterradas, pela exposição dessas obras à ação de intempéries (temperatura, precipitação, insolação, vento etc.), o que pode gerar o seu desgaste ou até mesmo danos maiores.

Assim, destaca-se aqui o mapeamento da erosividade e da erodibilidade ao longo de obras enterradas, referentes ao Oleoduto São Paulo - Brasília (OSBRA), administrado pela Petrobras. Tal obra atravessa extensa área produtiva entre os municípios de Paulínia-SP e Brasília-DF, cortando inúmeros municípios nos estados de Minas Gerais e Goiás. São discutidos resultados de parte de uma pesquisa realizada ao longo da dutovia OSBRA, no trecho situado desde Goiás até Minas Gerais, totalizando $535 \mathrm{~km}$, mapeado a partir da delimitação de bacias hidrográficas no entorno de tais obras. $\mathrm{O}$ intuito foi indicar as áreas com maior suscetibilidade à erosão hídrica, de modo a subsidiar diretrizes de proteção e manejo frente à ocorrência de processos erosivos. Logo, inicialmente são apresentados conceitos relativos à erosividade e à erodibilidade.

\section{Erosividade}

A erosividade é um índice numérico que expressa o potencial da água da chuva em causar a erosão (desagregação do solo) numa área desprovida de cobertura vegetal, com as mesmas condições de inclinação e tipo de solo.

Wischmeier e Smith (1978) consideraram que esse potencial poderia ser correlacionado ao produto entre a energia cinética $(\mathrm{Ec})$, liberada pelo impacto das gotas da chuva, e a intensidade máxima da chuva em qualquer período de 30 minutos consecutivos $\left(\mathrm{I}_{30}\right)$, produto esse denominado de índice de erosividade, segundo a Eq. 1, a seguir.

$$
\mathrm{EI}_{30}=\mathrm{Ec} \times \mathrm{I}_{30}
$$

onde:

$\mathrm{EI}_{30}=$ índice de erosividade em 30 minutos;

$\mathrm{Ec}=$ energia cinética, dada em $\mathrm{MJ} \mathrm{ha}^{-1}$;

$\mathrm{I}_{30}=$ intensidade máxima da chuva em qualquer período de 30 minutos consecutivos, dada em $\mathrm{mm} \mathrm{h}^{-1}$. 
Para o cálculo da energia cinética (Ec) da chuva, Wischmeier e Smith (1978) estabeleceram uma equação, posteriormente adaptada e dimensionada em unidades do sistema internacional por Foster et al. (1981) na seguinte forma:

$$
\mathrm{Ec}=0,119+0,0873 \log _{10} \mathrm{I}
$$

onde:

$\mathrm{Ec}=$ energia cinética, dada em MJ ha ${ }^{-1} \mathrm{~mm}^{-1}$;

$\mathrm{I}=$ intensidade da chuva, em $\mathrm{mm} / \mathrm{h}$.

Métodos diretos de cálculo da energia cinética da chuva na deflagração de processos erosivos devem basear-se nas características físicas da chuva, como a distribuição do tamanho de gotas, um procedimento de difícil simulação. Contudo, conforme exposto por Oliveira, Wendland e Nearing (2012), diversos trabalhos compararam a energia cinética de amostras de tamanho de gotas de chuva com o valor encontrado pela fórmula desenvolvida por Wischmeier e Smith (1978) e concluíram que existe grande similaridade entre eles.

Com a soma dos valores de $\mathrm{EI}_{30}$ de todas as chuvas erosivas ao longo de um mês, obtém-se a erosividade mensal, enquanto o somatório dos valores mensais de $\mathrm{EI}_{30}$ ao longo do ano corresponde ao valor de erosividade anual. Por sua vez, calculando-se a média de erosividade anual ao longo de uma série temporal de, no mínimo, vinte anos, obtém-se o valor de erosividade média, que consiste no fator R da Equação Universal de Perdas de Solo (EUPS), expresso em MJ.ha ${ }^{-1} \mathrm{~mm} \cdot \mathrm{h}^{-1}$.

Entretanto, para o cálculo da intensidade das chuvas, são necessários registros pluviográficos, os quais ainda podem ser considerados incipientes no Brasil, pela baixa densidade da rede de pluviógrafos instalados, pelo curto período de observações disponíveis ou mesmo pela dificuldade de processamento para geração de dados em formato digital (OLIVEIRA; ANTONINI; GRIEBELER, 2008).

Além disso, o $\mathrm{EI}_{30}$ não apresenta boa correlação com as perdas de solo nas regiões tropicais, uma vez que a fórmula desenvolvida por Wischmeier e Smith (1978) para os Estados Unidos subestima a capacidade das chuvas tropicais em promover a desagregação e o transporte da camada superficial do solo (MARQUES; ALVARENGA; CURI, 1998). Sobre isso, Marques, Alvarenga e Curi (1998) apontam para o fato "das chuvas tropicais tornarem-se erosivas somente quando em intensidade superior a $25 \mathrm{~mm} \mathrm{~h}^{-1}$ e serem observadas chuvas com intensidade várias vezes superior às das chuvas das regiões temperadas".

Por tal motivo, modelos de regressão mais simplificados, capazes de serem relacionáveis ao $\mathrm{EI}_{30}$ e que se valem de dados pluviométricos (registros mensais e anuais), foram desenvolvidos. Ressalta-se ainda, para o caso das regiões intertropicais, a 
aplicação do cálculo da intensidade pluviométrica, sugeridos por Crepani, Medeiros e Palmeira (2004). Esses autores definem a intensidade pluviométrica como sendo a razão entre pluviosidade anual e duração do período chuvoso, capaz de refletir o grau de suscetibilidade de determinada localidade aos processos erosivos. Segundo os autores, condições de elevada pluviosidade anual em uma curta duração do período chuvoso indicam chuvas mais intensas, ou seja, um maior volume de água precipitada em menor intervalo de tempo que, por sua vez, sugere maior quantidade de energia para desagregação e maior volume para o escoamento superficial. Com base nesse princípio, Crepani et al. (2001) construíram uma escala intensidade pluviométrica, que corresponde à uma escala de erosividade, variando entre 1 e 3 , correspondente à vulnerabilidade do terreno à perda de solo pela ação da chuva.

O coeficiente de chuva consiste em um exemplo desses modelos amplamente empregados (LOMBARDI NETO; MOLDENHAUER, 1992; BERTOL, 1993; BERTOL, 1994; ALMEIDA et al., 2011; ALMEIDA, et al. 2012; SILVA; IORI; SILVA, 2009; ROQUE; CARVALHO; PRADO, 2001; SILVA, et al. 1997; BAZZANO; ELTZ; CASSOL, 2010; COLODRO et al., 2002; SILVA; DIAS, 2003; MELLO, et al., 2007).

Também conhecido por índice de Fournier, o coeficiente de chuva (FOURNIER, 1960) baseia-se no princípio de que o volume e a intensidade da chuva são capazes de refletir o volume de escoamento superficial, estimando melhor as perdas de solo. Esse coeficiente foi adaptado posteriormente por Lombardi Neto e Moldenhauer (1992), para o cálculo a partir da razão entre o quadrado da precipitação média mensal e a média anual.

$$
\mathrm{Cc}=\mathrm{p}^{2} / \mathrm{P}
$$

onde:

$\mathrm{Cc}=$ coeficiente de chuva, dado em $\mathrm{mm}$;

$\mathrm{p}$ = precipitação média mensal, em mm;

$\mathrm{P}=$ precipitação média anual, em $\mathrm{mm}$.

Carvalho et al. (1991), Rufino, Biscaia e Merten (1993), Marques, Alvarenga e Curi (1998), Roque, Carvalho e Prado (2001) encontraram correlações altamente significativas entre o coeficiente de chuva $(\mathrm{Cc})$ e o índice de erosividade $\left(\mathrm{EI}_{30}\right)$ para as respectivas localidades do país analisadas.

De outro modo, Lombardi Neto e Moldenhauer (1992) desenvolveram um índice de erosão (EI) baseado no cálculo do coeficiente de regressão entre o coeficiente de chuva $(\mathrm{Cc})$ e o índice médio mensal de erosão $\left(\mathrm{EI}_{30}\right)$ que, ao ser aplicado para Campinas-SP, apresentou alto coeficiente de correlação $(\mathrm{R}=0,983)$, conforme a equação: 


$$
\mathrm{EI}=68,730\left(\mathrm{p}^{2} / \mathrm{P}\right)^{0,841}
$$

onde:

EI - índice de erosividade média mensal, dado em MJ mm.ha ${ }^{-1}$.mês ${ }^{-1}$;

p - precipitação média mensal, em mm;

$\mathrm{P}$ - precipitação média anual, em mm.

Do somatório de todos os EI médios mensais ao longo do ano, obtém-se o índice de erosão anual. Vale destacar que, para uma melhor correlação entre o Cc com o $\mathrm{EI}_{30}$, são aplicados diferentes coeficientes de ajustes, conforme as condições climáticas de cada localidade, principalmente referente à média pluviométrica anual e à latitude. Oliveira, Wendland e Nearing (2012) apresentam uma abrangente revisão sobre diversas equações adaptadas e os respectivos valores de erosividade encontrados para diferentes localidades do território brasileiro, dos quais se enumeram os índices de erosividade referentes às proximidades da área em estudo, variando desde $11.635 \mathrm{MJ} \cdot \mathrm{mm} \cdot \mathrm{ha}^{-1} \cdot \mathrm{ano}^{-1}$, para Brasília-DF (DEDECEK, 1988); 10.300 MJ.mm.ha- ${ }^{-1}$.ano-1, para o Tocantins (VIOLA et al., 2014); até 10.440 MJ.mm.ha ${ }^{-1}$.ano ${ }^{-1}$, para o Pantanal (MACHADO et al., 2014); e 9.810 MJ.mm.ha ${ }^{-1}$.ano ${ }^{-1}$, para o triângulo mineiro (MELLO et al., 2007).

Segundo Silva (2004), vários autores encontraram boas correlações entre o índice de Fournier e os índices de erosão, conforme o visto no alto valor de correlação encontrado por Lombardi Neto e Moldenhauer (1992). Entretanto, vários trabalhos destacam a falta de uma maior atenção dada às propriedades de cada chuva, com relação à sua capacidade erosiva, principalmente no que se refere à suas características de duração, intensidade e frequência. Considerando a pouca disponibilidade de registros pluviográficos, ao serem consideradas as ressalvas a respeito dos tipos de chuvas e de sua variabilidade temporal, os indícios podem ser mais satisfatórios. Sobre isso, Dedecek (1988) comenta que "para uma mesma intensidade da chuva, a capacidade erosiva da chuva varia de acordo com seu tipo (convectiva, frontal etc.)".

As chuvas frontais ocorrem pelo encontro de massas de ar com características térmicas distintas; as orográficas originam-se quando uma massa de ar úmida ascende uma barreira topográfica; e as convectivas formam-se pela ascensão por aquecimento e posterior condensação do ar. Sabe-se que as chuvas frontais e as orográficas apresentam longa duração e menor intensidade, ao passo que as chuvas convectivas possuem menor duração e maior intensidade. Portanto, o tipo de chuva dá indícios correlacionáveis à intensidade e à duração das chuvas, e, consequentemente, de seu poder erosivo, que pode ser analisado em conjunto com o regime das chuvas ao longo das estações do ano, visto que ocorre o predomínio de cada tipo de chuva conforme determinada estação sazonal.

Ao mensurar diversos índices de erosividade e perdas de solo conforme os diferentes tipos de chuva na região do bioma Cerrado, Dedecek (1988) destaca que as chuvas convectivas, de maior intensidade e menor duração, são aquelas que apresentam 
maior capacidade erosiva. Contudo, esse autor frisa que as chuvas frontais, de menor intensidade e maior duração, são aquelas que apresentam maior volume de escoamento superficial e, consequentemente, maiores perdas de solo. Isso ocorre pelo fato das chuvas frontais ocorrerem em maior quantidade de dias consecutivos. Além disso, na estação chuvosa o solo encontra-se mais saturado, o que favorece o escoamento superficial da água. Sobre isso, o autor enfatiza que

\begin{abstract}
enquanto as chuvas convectivas podem ocorrer em intervalos de até 37 dias e as frontais não ultrapassam oito dias, com base nas 58 chuvas convectivas tem-se que, em média, são necessários $79 \mathrm{~mm}$ de chuva para causar a perda de 1 tonelada de solo e de $74 \mathrm{~mm}$ para 1 milímetro de enxurrada. Em média, são necessários apenas $41 \mathrm{~mm}$ e $49 \mathrm{~mm}$ de chuva para provocar a perda de 1 tonelada de solo e de 1 milímetro de enxurrada, respectivamente, considerando-se as 58 chuvas frontais (DEDECEK, 1988, p.1433).
\end{abstract}

Por tal motivo, análises climatológicas referentes à dinâmica e à atuação dos sistemas atmosféricos, responsáveis pela gênese dos tipos de tempo e, por conseguinte, das chuvas, são necessárias, paralelamente aos levantamentos de erosividade, para uma melhor fundamentação da análise da capacidade da chuva em deflagrar processos erosivos.

\title{
Erodibilidade
}

A erodibilidade dos solos baseia-se na resistência ou vulnerabilidade do solo à desagregação e ao subsequente transporte de suas partículas. É avaliada com base nas propriedades físicas, biológicas e químicas do solo, além das propriedades mecânicas e hidrológicas, principalmente no que se refere à velocidade de permeabilidade, infiltração e capacidade de armazenamento de água, associada à resistência à desagregação e ao transporte pelo impacto da gota da chuva e pelo escoamento superficial.

$\mathrm{O}$ mapeamento da suscetibilidade à erosão com base na quantificação da erodibilidade diretamente em campo, como a análise das chuvas, naturais ou simuladas, pode ser considerado dispendioso e demorado (SCOPEL; SILVA, 2001). Levando em conta esse fato, a espacialização da erodibilidade pode ser realizada com base na consideração indireta e estimativa das diversas propriedades do solo.

Segundo sugerido por Bertoni e Lombardi Neto (2010), o valor de erodibilidade pode ser determinado num intervalo entre 0 e 1 e ainda a erodibilidade ser classificada em: baixa $(<0,15)$, média $(0,15$ a 0,30$)$ ou alta $(>0,30)$, dentro desse intervalo (CARVALHO, 1994). Em relação à interpretação e à classificação dos valores de erodibilidade, Silva e Alvares (2005) sugeriram, para solos do estado de São Paulo, a classificação de erodibilidade baixa para os valores menores que 0,01529 ; média para os valores situados no intervalo entre 0,01529 e 0,03058 ; e alta para os valores maiores que 0,03058 t.ha ${ }^{-1} \cdot \mathrm{MJ}^{-1} \cdot \mathrm{mm}^{-1}$. 
Dentre as propriedades físicas do solo cujas análises possibilitam a estimativa indireta da erodibilidade, destacam-se a textura e a estrutura do solo, as quais correspondem à distribuição e ao arranjo das partículas do solo, conforme seu tamanho. A análise de tais propriedades permite o entendimento da capacidade de desagregação e de infiltração da água, em confronto com a ação do escoamento superficial e posterior transporte das partículas do solo. Uma forma consagrada de estimativa indireta de erodibilidade, baseada nas propriedades de textura, matéria orgânica, estrutura e permeabilidade, é o Diagrama desenvolvido por Wischmeier e Smith (1978) e modificado por Scopel e Silva (2001).

Exemplificando-se, quanto à textura do solo, é possível estimar-se que a erodibilidade tende a ser mais elevada em solos com maior teor de silte e areia fina em comparação àqueles onde predomina argila e/ou areia com diâmetro maior que $0,1 \mathrm{~mm}$ (FERREIRA et al., 2002). Em geral, os grãos de areia com diâmetro maior que $0,1 \mathrm{~mm}$ resistem ao transporte, enquanto solos argilosos resistem à desagregação.

Em se tratando em específico da estrutura do solo, estimativas podem ser realizadas, em associação com análises do escoamento superficial e da infiltração da água, comandados também pela porosidade e pela permeabilidade do material. Cita-se, por exemplo, o caso do maior conteúdo de argilas em solos mais desenvolvidos, como os Latossolos. Ferreira et al. (2002) destacam que as agregações presentes nesse tipo de solo, com quantidades expressivas de óxidos e hidróxidos de ferro e alumínio, possuem formatos mais arredondados, com baixa coerência entre essas agregações, facilitando assim a ação da água no arraste das partículas e, consequentemente, aumentando a sua erodibilidade.

A análise das propriedades mineralógicas, em associação com as propriedades físicas permitem também inferências quanto à permeabilidade, que pode ser correlacionada à erodibilidade dos solos. Ferreira; Fernandes; Curi (1999), comparando a mineralogia de Latossolos e observando propriedades físicas, destacaram que os cauliníticos apresentaram maior densidade do solo, menor estabilidade das agregações em água, menor macroporosidade e, consequentemente, menor permeabilidade, quando comparados com os gibbsíticos. Comparando o teor de argila nesses mesmos solos, Ferreira; Fernandes; Curi (1999) afirmaram ainda que os Latossolos apresentaram maior permeabilidade para solos mais argilosos.

No que concerne às propriedades biológicas, ressalta-se o teor de matéria orgânica, o qual auxilia na agregação das partículas do solo; e a ação de raízes e de animais na formação de macroporos, o que aumenta a capacidade de infiltração. Com relação às propriedades químicas, Guerra (2012) chama a atenção para o teor de carbono orgânico, responsável pela formação de agregações, que aumentam a resistência do solo e a auxiliam na infiltração da água.

Em relação à magnitude dos valores de erodibilidade encontrados na bibliografia especializada, Ferreira et al. (2002) estimaram, com base em atributos morfológicos, físicos, químicos e mineralógicos determinados em laboratório, um fator de erodibilidade (K) de 0,019 t.h.(MJ.mm) ${ }^{-1}$ para solos do tipo Nitossolo, localizados no 
município de Perdões, MG. Segundo esses autores, esses solos possuem uma mineralogia caulínitica, apresentando uma estrutura bem definida em blocos subangulares, e, por isso, são mais erodíveis superficialmente que os Latossolos. Os Nitossolos foram classificados por eles como de moderada erodibilidade, enquanto os Latossolos, de baixa erodibilidade.

Para solos do tipo Latossolo, localizados no município de Lavras, MG, o fator de erodibilidade estimado por eles foi de 0,001 t.h.(MJ.mm)-1 , ou seja, quase 20 vezes menor que o encontrado para o Nitossolo. Em um levantamento realizado por Silva et al. (1999), citando trabalhos que realizaram medições diretas em solos brasileiros pelo método da chuva natural, um solo do tipo Latossolo Vermelho-Escuro de textura argilosa, localizado em Goiânia-GO, apresentou um valor de erodibilidade de 0,009 t.h.MJ ${ }^{-1} \cdot \mathrm{mm}^{-1}$.

Quanto à erodibilidade de solos do tipo Neossolo Flúvico, Carmo e Val (2013) constataram que a textura e o conteúdo de matéria orgânica desses materiais oscilam de acordo com as características do curso d'água na deposição de sedimentos durante as cheias pretéritas. Silva (2004), ao estimar a erosão atual da bacia do rio Paracatu, na divisa entre GO e MG, apresentou um valor médio de erodibilidade de $0,042$ t.h.(MJ.mm) $)^{-1}$, para esse tipo de solo.

Para solos do tipo Gleissolo, desenvolvidos em condições hidromórficas, Chaves et al. (2010) determinaram valores de erodibilidade, para a solos de perfis localizados na bacia hidrográfica do rio Jardim, no DF, com base no teor de argila contido no horizonte superficial de cada perfil, entre 0,004531 e 0,0053 t.h.MJ ${ }^{-1} \cdot \mathrm{mm}^{-1}$.

Solos jovens como os do tipo Neossolo Litólico e Cambissolo podem ser considerados como de alta erodibilidade. Os primeiros são solos rasos, pouco evoluídos, por muitas vezes correspondendo a afloramentos rochosos, com textura relacionada ao material de origem, apresentando baixa à nula taxa de infiltração, cujo valor determinado por Bloise et al. (2001) foi de 0,0368 t.h/(MJ.mm). Os segundos, tem valores altos de erodibilidade por apresentarem em geral teores mais altos de silte, em sua maioria apresentando menores taxas de infiltração por possuírem pequenas espessuras das camadas mais intemperizadas, cujos valores, apresentados por Bloise et al. (2001) variam de 0,0158 à 0,0263 .

\section{Materiais e Métodos}

O nome OSBRA é a sigla para Oleoduto São Paulo/Brasília, que transporta produtos claros, álcool e gás liquefeito de petróleo (GLP) e atravessa os estados de São Paulo, Minas Gerais e Goiás, além do Distrito Federal, com 970 km de extensão. No presente trabalho foi considerado apenas o trecho que parte das divisas dos estados de São Paulo e Minas Gerais e atravessa o estado de Goiás, chegando ao Distrito Federal, totalizando um segmento de $535 \mathrm{~km}$. Com vistas a facilitar descrição regional, o segmento do duto OSBRA considerado no presente trabalho foi dividido em cinco quadrantes, conforme a definição dos trechos administrados pelas regionais da Petrobras. A parte considerada nesse estudo inicia-se na borda do município de Ribeirão Preto-SP, 
com término em Brasília-DF, o que corresponde aos trechos numerados de três a sete de todo o segmento do duto OSBRA.

Para o mapeamento da erosividade, foram empregados dados de 20 estações meteorológicas na proximidade do duto que foram utilizadas pelo Serviço Geológico do Brasil (CPRM, 2015) para realização do projeto "Atlas Pluviométrico do Brasil". Com base na localização dessas estações, foram delimitados polígonos de Thiessen, que correspondem às áreas de influência de cada estação meteorológica até a existência de outra adjacente. Nesse método, os polígonos delimitados representam os domínios nos quais os dados registrados pelos instrumentos meteorológicos podem ser considerados (GALDINO, 2015).

Com base nas médias mensais e anuais de precipitação de uma série temporal de 1977 a 2006 (29 anos), os valores de erosividade para cada estação meteorológica foram calculados pelo software Excel (Microsoft, 2010). Para tanto, empregou-se a equação de índice de erosão (EI), desenvolvido por Lombardi Neto e Moldenhauer (1992) e adaptada por Cabral et al. (2005), conforme as condições climáticas locais da região de Morrinhos-GO, município localizado na porção central da área em estudo, segundo a equação:

$$
\mathrm{EI}=67.355\left(\mathrm{r}^{2} / \mathrm{P}\right)^{0,85}
$$

onde:

$\mathrm{EI}=$ média mensal do índice de erosão em $\mathrm{MJ} \mathrm{ha}^{-1} \mathrm{~mm} \mathrm{~h}^{-1} \mathrm{mês}^{-1}$;

$\mathrm{r}=$ precipitação média mensal em milímetros;

$\mathrm{P}=$ precipitação media anual em milímetros.

Por sua vez, a partir do mapeamento dos tipos de solo disponível em escala de 1:250.000, a erodibilidade foi definida com base no agrupamento de solo com comportamentos semelhantes quanto à resistência aos processos erosivos e pelos pressupostos estabelecidos por Salomão (2007) e Salomão et al. (2012), e posterior classificação de sua suscetibilidade erosiva. Considerando as principais ocorrências de tipos de solo, conforme as escalas de mapeamento disponíveis compiladas, destacam-se as categorias classificadas como erodibilidade "muito alta", Neossolo Litólico e Cambissolo; como erodibilidade "média" as categorias Argissolo, Nitossolo Vermelho e Chernossolo Argilúvico. Ficaram classificados como erodibilidade "baixa" os solos do tipo Latossolo, Plintossolo Pétrico e Gleissolo. O recorte espacial para a classificação da erodibilidade correspondeu às bacias hidrográficas de segunda ordem, interceptadas pelo duto OSBRA.

\section{Resultados e Discussão}

O índice de erosividade média anual das estações interceptadas pelo duto OSBRA é de $12.053 \mathrm{MJ} \cdot \mathrm{mm} \cdot \mathrm{ha}^{-1} \cdot \mathrm{h}^{-1} \cdot \mathrm{ano}^{-1}$. Contudo, em algumas estações esse valor pode chegar aos 16.589 MJ.mm.ha ${ }^{-1} \cdot \mathrm{h}^{-1}$. ano ${ }^{-1}$, como é o caso da estação de Piracanjuba$\mathrm{GO}$, localizada na porção centro-norte, enquanto outros locais não ultrapassam o valor 
de 10.200 MJ.mm.ha ${ }^{-1} \cdot h^{-1} \cdot$ ano $^{-1}$, como visto em Tupaciguara-MG, na região centro-sul da área em estudo.

Conforme observado no mapa representado na Figura 1, os maiores índices de erosividade são vistos na porção central da área em estudo, especificamente na divisa entre os trechos 6 e 5, referente à estação de Piracanjuba-GO. Valores também consideráveis são vistos próximos a essa localidade (noroeste do trecho 6), assim como na divisa dos estados de Goiás e Minas Gerais (sul do trecho 5) e entre Minas Gerais e São Paulo (nordeste do trecho 3). Os menores índices de erosividade podem ser verificados na porção central do segmento do duto (divisa de Goiás e Minas Gerais). Os índices de erosividade média anual de cada estação meteorológica também podem ser vislumbrados pela Tabela 01 .

A maior erosividade mensal ocorre em janeiro e dezembro, com média de 3.209,4 e 2.941,2 MJ.mm.ha ${ }^{-1} \cdot \mathrm{h}^{-1} \cdot \mathrm{ano}^{-1}$, respectivamente. Nesses meses, os valores de erosividade podem alcançar o máximo de $4.555,4 \mathrm{MJ} \cdot \mathrm{mm} \cdot \mathrm{ha}^{-1} \cdot \mathrm{h}^{-1} \cdot$ ano $^{-1}$, conforme visto durante janeiro em Goianápolis-GO. Os valores em fevereiro, março e novembro também são consideráveis, variando entre $1.667,1 \mathrm{e} 1.589,8 \mathrm{MJ} \cdot \mathrm{mm} \cdot \mathrm{ha}^{-1} \cdot \mathrm{h}^{-1} \cdot \mathrm{ano}^{-1}$, mas podendo atingir o máximo de 2.662,2 MJ.mm.ha ${ }^{-1} \cdot \mathrm{h}^{-1}$.ano ${ }^{-1}$, conforme média para março em Piracanjuba-GO. Os valores de erosividade entre abril e outubro são irrisórios, com média em 497,4 e 2,4 MJ.mm.ha ${ }^{-1} \cdot \mathrm{h}^{-}$ ${ }^{1}$.ano ${ }^{-1}$ e não ultrapassando o máximo de $762,3 \mathrm{MJ} \cdot \mathrm{mm} \cdot \mathrm{ha}^{-1} \cdot \mathrm{h}^{-1}$.ano ${ }^{-1}$ e podendo atingir o mínimo de $0,1 \mathrm{MJ} \cdot \mathrm{mm} \cdot \mathrm{ha}^{-1} \cdot \mathrm{h}^{-1} \cdot$ ano $^{-1}$, como mostrado na Tabela 02 .

Tabela 01. Índice de erosividade média para as estações meteorológicas ao longo do duto OSBRA

\begin{tabular}{lcc}
\hline Código & Município & Índice de Erosividade (EI) média anual (MJ.mm.ha $^{-1} \mathbf{h}^{\mathbf{1}} \mathbf{a n o}^{\mathbf{- 1}}$ ) \\
\hline 1548001 & $\begin{array}{c}\text { Mimoso de } \\
\text { Goiás }\end{array}$ & $10.516,40$ \\
\hline 1647003 & Luziânia & $11.545,09$ \\
\hline 1648001 & Alexânia & $11.499,52$ \\
\hline 1649009 & Anápolis & $13.012,60$ \\
\hline 1649004 & Goianápolis & $11.865,31$ \\
\hline 1649012 & Trindade & $12.288,70$ \\
\hline 1649001 & Aragoiânia & $12.343,79$ \\
\hline 1748000 & Cristianópolis & $11.387,80$ \\
\hline 1749005 & Piracanjuba & $16.589,84$ \\
\hline 1749003 & Morrinhos & $11.876,18$ \\
\hline 1848007 & Buriti Alegre & $10.581,14$ \\
\hline 1848008 & Tupaciguara & $13.259,46$ \\
\hline 1848006 & Tupaciguara & 11.853 .67 \\
\hline 1848004 & Tupaciguara & $10.200,85$ \\
\hline
\end{tabular}




\begin{tabular}{lcc}
\hline Código & Município & Índice de Erosividade (EI) média anual (MJ.mm.ha $^{-1} \mathbf{h}^{-1} \mathbf{a n o}^{-1}$ ) \\
\hline 1848009 & Uberlândia & $11.751,05$ \\
\hline 1948006 & Uberlândia & $11.546,47$ \\
\hline 1948007 & Campo Florido & $12.034,12$ \\
\hline 1747007 & Perdizes & $12.909,33$ \\
\hline 1747008 & Sacramento & $12.444,62$ \\
\hline 2047007 & Ituverava & $11.555,40$
\end{tabular}

Fonte: calculada pelos autores a partir de CPRM (2015).

Tabela 02. Valores mensais de índice de erosividade (MJ mm ha $\left.{ }^{-1} \mathrm{~h}^{-1} \mathrm{ano}^{-1}\right)$.

\begin{tabular}{|c|c|c|c|c|}
\hline \multirow{2}{*}{ MÊS } & \multicolumn{2}{|c|}{ Médio } & \multirow{2}{*}{ Máximo } & \multirow{2}{*}{ Mínimo } \\
\hline & Absoluto & Relativo *(\%) & & \\
\hline Jan & $3.209,4$ & 26,6 & $4.555,4$ & $2.253,2$ \\
\hline $\mathrm{Fev}$ & $1.589,8$ & 13,2 & $2.167,3$ & $1.216,7$ \\
\hline Mar & $1.667,1$ & 13,8 & $2.662,2$ & $1.212,6$ \\
\hline Abr & 290,4 & 2,4 & 494,1 & 168,2 \\
\hline Mai & 58,79 & 0,5 & 106,6 & 29,3 \\
\hline Jun & 7,0 & 0,1 & 18,8 & 1,2 \\
\hline \multirow{2}{*}{ MÊS } & \multicolumn{2}{|c|}{ Médio } & \multirow{2}{*}{ Máximo } & \multirow{2}{*}{ Mínimo } \\
\hline & Absoluto & Relativo *(\%) & & \\
\hline Jul & 2,4 & 0,0 & 6,8 & 0,1 \\
\hline Ago & 10,2 & 0,1 & 22,0 & 4,5 \\
\hline Set & 104,9 & 0,9 & 168,5 & 60,0 \\
\hline Out & 497,4 & 4,0 & 762,3 & 64,8 \\
\hline Nov & $1.629,5$ & 13,5 & $2.147,3$ & $1.186,7$ \\
\hline Dez & $2.941,2$ & 24,4 & $4.188,3$ & $2.405,4$ \\
\hline Total & $12.053,1$ & 100,0 & $16.589,8$ & $10.200,8$ \\
\hline
\end{tabular}

Fonte: calculada pelos autores a partir de CPRM (2015).

A variabilidade intranual dos índices de erosividade reflete a sazonalidade marcante das chuvas na região em estudo, que repercute na concentração dos eventos chuvosos durante os meses da primavera e do verão (outubro a março).

Vale destacar que apesar dos valores de erosividade não serem elevados durante os meses de setembro e outubro, é nesses meses que ocorrem as primeiras chuvas do período chuvoso da área em estudo. Quando ocorrem as chuvas de grande intensidade, o solo desta região, que tem características de solos não saturados, tem em seus poros a 
presença do ar, que, no primeiro momento, dificulta a infiltração da água, aumentando o escoamento superficial.

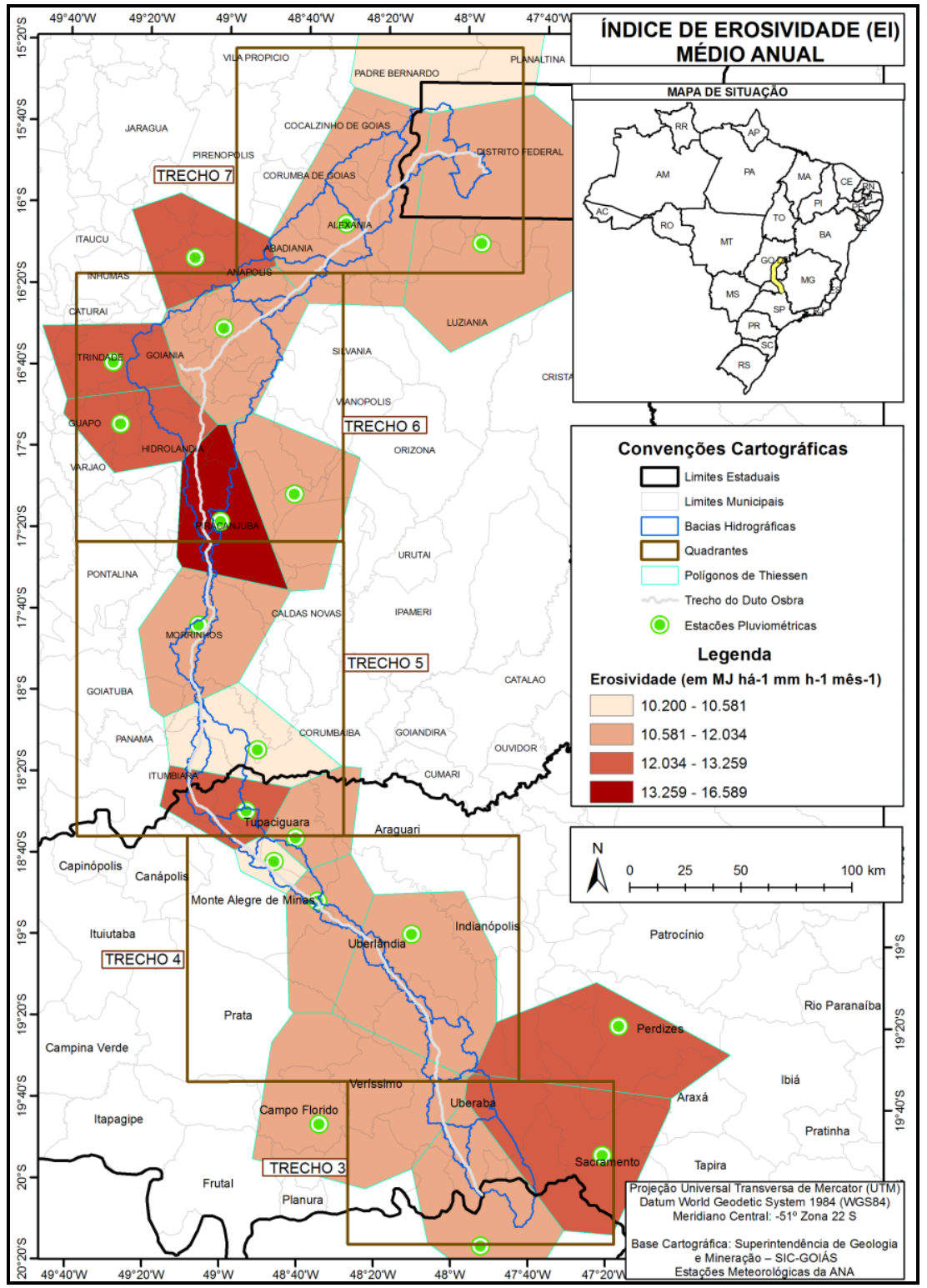

Figura 01. Mapa de erosividade ao longo do duto OSBRA.

Org.: NASCIMENTO, D. T. F; ROMÃO, P; A; SALES, M. M. 
Durante o inverno, devido ao menor ângulo de incidência da radiação solar, a superfície terrestre encontra-se menos aquecida. Por conta disso, a zona de alta pressão localizada no Atlântico Sul, de onde deriva a massa tropical atlântica $(\mathrm{mTa})$, torna-se fortalecida e avança em sentido SE-NO, predominando na região de estudo e repercutindo tempo estável, céu claro, baixa umidade e moderadas temperaturas. Fortalecida pelo sentido de deslocamento da $\mathrm{mTa}$, a massa polar $(\mathrm{mP})$ facilmente se desloca e alcança a região, ocasionando considerável diminuição das temperaturas e fornecendo umidade por onde chega. Ao chegar em locais com temperaturas mais elevadas, ocorre a frontogênese, resultando em chuvas frontais, de longa duração e baixa intensidade (SERRA; RATISBONNA, 1942; NIMER, 1979; AYOADE, 2003).

Por sua vez, durante o verão, o maior ângulo de incidência da radiação solar ocasiona num maior aquecimento da superfície terrestre com relação à oceânica. Devido a esse aquecimento desigual, a zona de baixa pressão localizada na região amazônica se expande e domina por grande parte do território brasileiro, intensificando a atuação da massa equatorial continental $(\mathrm{mEc})$ sobre praticamente todo o país - o que condiciona o período chuvoso. Por ter origem em uma área de baixa pressão localizada na Floresta Amazônica, essa massa de ar apresenta movimento ascendente e convergente, concentrando a umidade fornecida pela evapotranspiração da densa vegetação e abundantes corpos hídricos da Floresta Amazônica e transmitindo-a para as demais regiões do país durante sua trajetória em sentido NO-SE até o litoral do sul do Brasil (SERRA; RATISBONNA, 1942; NIMER, 1979; AYOADE, 2003). Nesse período também atua a Zona de Convergência do Atlântico Sul (ZCAS), que se baseia em uma alongada banda de nebulosidade de orientação NO/SE que se estende desde o sul da região Amazônica até o oceano Atlântico Sul, sendo responsável pelo fornecimento de calor, umidade e convecção da região Amazônica às maiores latitudes (NIMER, 1979, KOUSKY, 1988).

Portanto, os elevados índices de erosividade observados nos meses do verão são justificados pelo predomínio das chuvas convectivas, de maior intensidade e maior capacidade erosiva, associadas às chuvas frontais, que, apesar de apresentarem menor intensidade, costumam ocorrer em praticamente todos os dias, o que implica na elevação do grau de saturação do solo. Por sua vez, o solo com alto teor de saturação dificulta a infiltração e também favorece o escoamento superficial, aumentando a suscetibilidade do solo em ser transportado. Além disso, o tipo de solo condiciona também uma maior ou menor resistência ao processo erosivo.

Ocorre nas bacias hidrográficas, ao longo do duto uma diversidade de categorias de solo, com predomínio do Latossolos (60,7\%), seguido pelos Cambissolos $(23,2 \%)$. Com expressiva ocorrência, encontram-se os Argissolos (11\%). Em menores proporções e totalizando apenas $1,7 \%$ da área, ocorrem os Chernossolo Argilúvico, Nitossolo Vermelho, Neossolo Litólico, Gleissolo (em associação com Neossolo Flúvico, por causa da escala de mapeamento). Conforme a Figura 2, os solos de baixa erodibilidade predominam ao longo do duto, correspondendo a $61,5 \%$ da área das bacias delimitadas. Os solos com elevada erodibilidade ocorrem sobre $23,6 \%$ da área em estudo, concentrando-se na porção norte (Trecho 7) e podendo ser vistos também na 
porção central (Trechos 6 e 5). Solos com média erodibilidade correspondem a 11,5\% da área, ocorrendo na porção central e sul do duto.

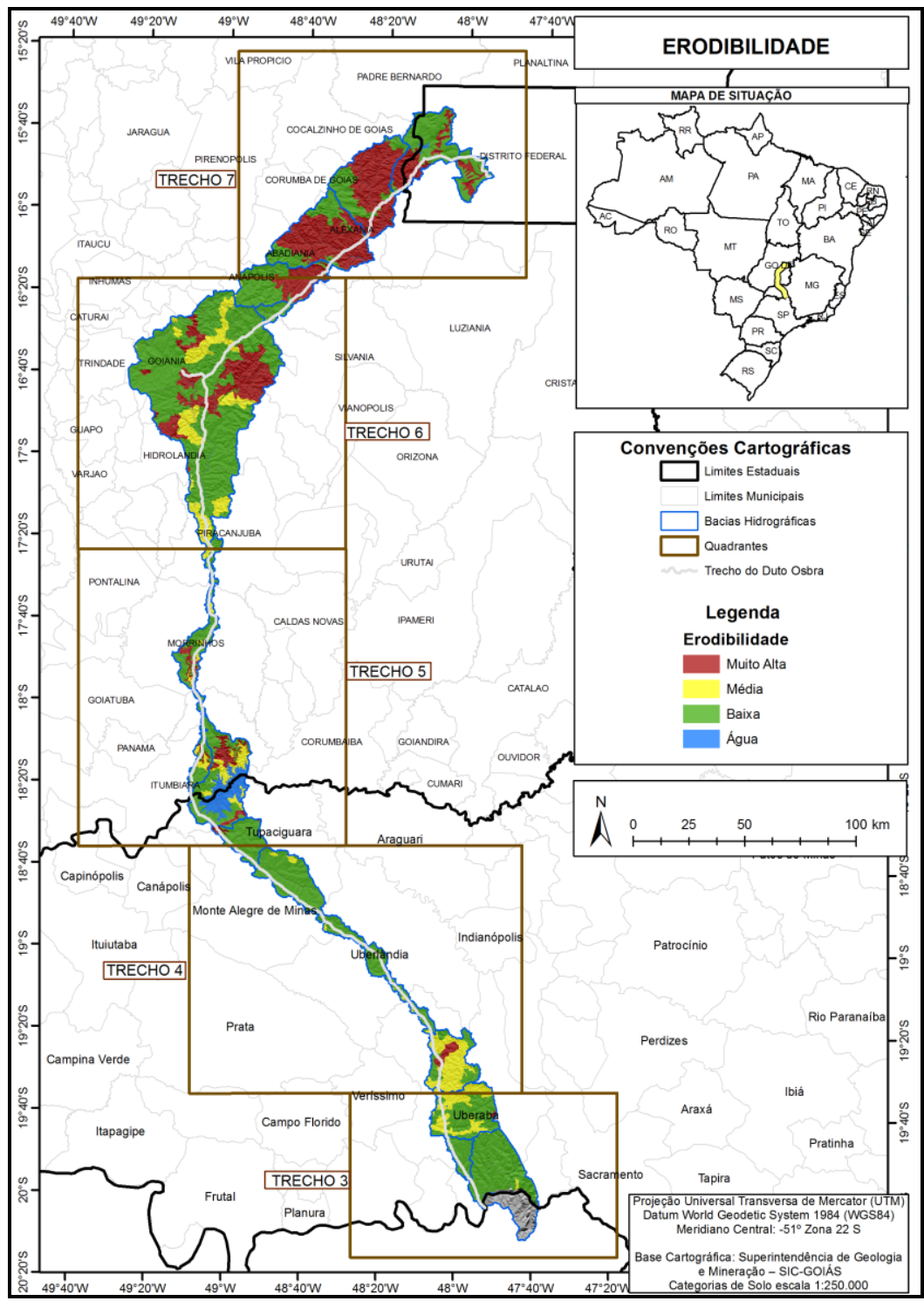

Figura 02. Erodibilidade nas bacias hidrográficas ao longo do duto OSBRA.

Fonte: organizada pelos autores. 
O mapa da Figura 3 apresenta a localização de 85 processos erosivos identificados por técnicos de inspeção da faixa e visitados pelos autores deste artigo, ao longo do duto OSBRA. A Figura 03 permite uma análise da variabilidade espacial da erosividade e da erodibilidade frente às ocorrências erosivas registradas, pela qual se pode perceber que a maioria das erosões ocorrem correlacionadas à alta e à média erodibilidade. Essa correlação ocorre ou pela influência dos maiores valores de erosividade, ou dos maiores valores de erodibilidade.

Isso enfatiza a importância do mapeamento das áreas de maior suscetibilidade aos processos erosivos, tanto em relação às condições climáticas, quanto aos tipos de solo, reforçando ainda a necessidade de investigação dos outros parâmetros que condicionam esse processo, como outras variáveis investigadas no âmbito do projeto em questão. Dentre essas variáveis, podem-se enumerar as morfométricas, que condicionam o escoamento superficial, tanto a velocidade quanto a concentração do fluxo superficial, bem como a energia potencial para ocorrência do fluxo, influenciando, portanto, nas condições de infiltração da água.

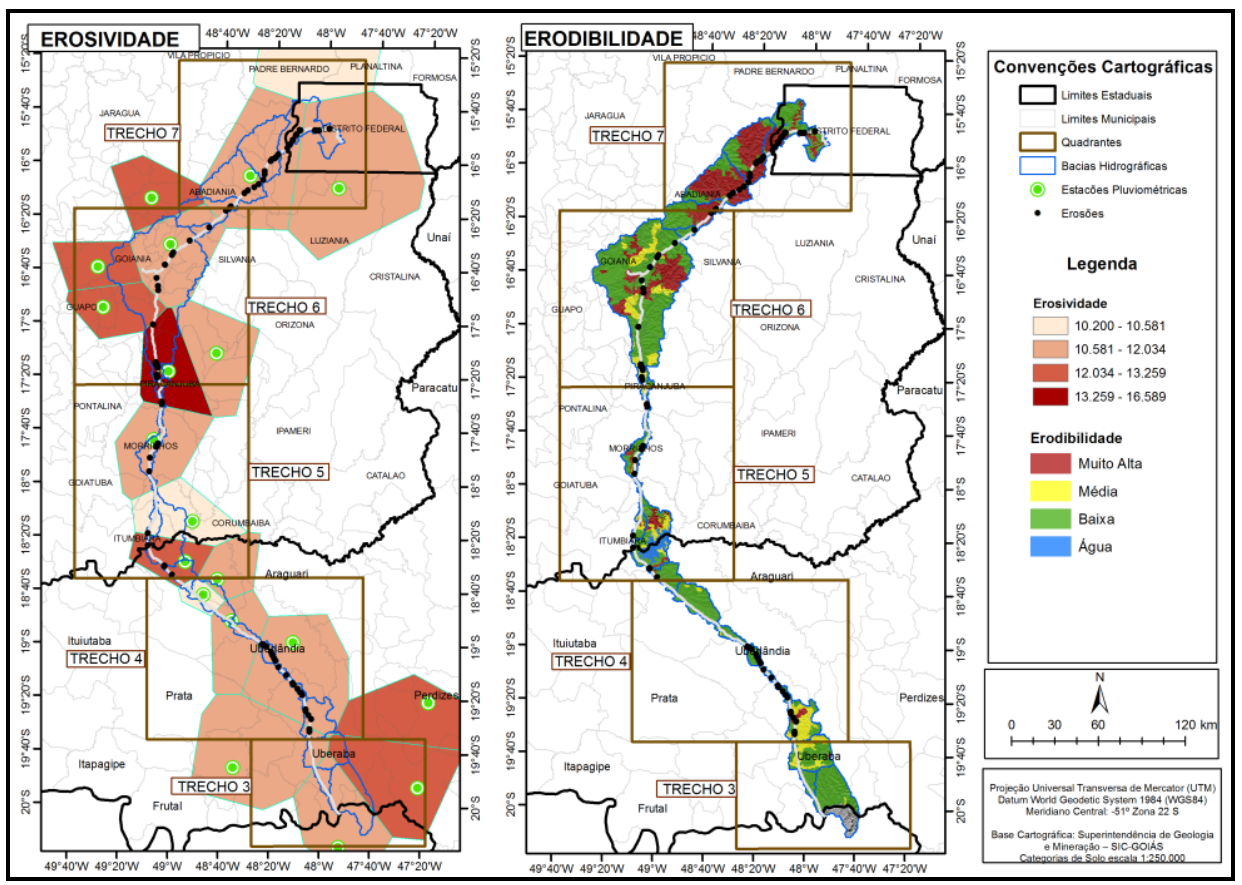

Figura 3. Erosividade e Erodibilidade com a indicação das ocorrências erosivas. Fonte: organizada pelos autores. 


\section{Considerações Finais}

1. Os mapeamentos de erosividade e erodibilidade são capazes de darem indícios relevantes ao conhecimento da suscetibilidade do solo aos processos erosivos, por representarem a capacidade da chuva e a resistência do solo em sofrer desagregação e transporte.

2. O conhecimento do processo erosivo e de seus condicionantes é fundamental para a conservação de solos para a manutenção de obras enterradas, bem como para a produção agrícola e atividade pecuária. Assim, a suscetibilidade avaliada para a faixa do presente objeto de estudo, que corta uma longa extensão de áreas produtivas, pode ser considerada quanto ao estudo das áreas adjacentes.

3. Com base na variação da erosividade e da erodibilidade ao longo do duto da Petrobras é possível destacar que as regiões norte e centro-norte (Trechos 7 e 6, respectivamente) oferecem maior suscetibilidade aos processos erosivos, por apresentarem os maiores índices de erosividade e elevada erodibilidade. Contudo outras áreas devem ser monitoradas, por apresentarem solos com média erodibilidade associados a valores consideráveis de erosividade, o que pode ser intensificado pelas atividades antrópicas.

\section{Referências}

ALMEIDA, Cristiana O. S.; AMORIM, Ricardo S. S.; COUTO, Eduardo G.; ELTZ, Flávio L.F.; BORGES, Laurienne E. C. Potencial erosivo da chuva de Cuiabá, MT: Distribuição e correlação com a precipitação pluviométrica. Revista Brasileira de Engenharia Agrícola e Ambiental. v.15, n.2, p. 178-184. 2011.

ALMEIDA, Cristiana O. S.; AMORIM, Ricardo S. S.; ELTZ, Flávio L. F.; COUTO, Eduardo G.; JORDANI, Sara A. Erosividade da chuva em municípios do Mato Grosso: distribuição sazonal e correlações com dados pluviométricos. Revista Brasileira de Engenharia Agrícola e Ambiental. v. 16, n. 2, p. 142-152, 2012.

AYOADE, J. O. Introdução à climatologia para os trópicos. 8. ed. Rio de Janeiro: Bertrand Brasil, 2003. 332 p.

BAZZANO, M. G. P.; ELTZ, F. L. F.; CASSOL, E. A. Erosividade e características hidrológicas das chuvas de Rio Grande (RS). Revista Brasileira de Ciências do Solo. n. 34, p. 235-244. 2010.

BERTOL, Ildegardis. Índice de erosividade $\left(\mathrm{EI}_{30}\right)$ para Lages $(\mathrm{SC})-1^{\mathrm{a}}$ aproximação. Pesquisa Agropecuária Brasileira. v. 28 n. 4. p. 515-521, 1993. 
BERTOL, Ildegardis.Avaliação da erosividade da chuva na localidade de Campos Novos (SC) no período de 1981 a 1990. Pesquisa Agropecuária Brasileira. v.29, n. 9, p. 1453$1458,1994$.

BERTOL, Ildegardis.; COGO, N. P.; SCHICK, J.; GUDAGNIN, J. C.; AMARAL, A. J. Aspectos financeiros relacionados às perdas de nutrientes por erosão hídrica em diferentes sistemas de manejo do solo. Revista Brasileira de Ciência do Solo [online]. v.31, n.1, p. 133-142, 2007.

BERTONI, José; LOMBARDI NETO, Francisco. Conservação do solo. São Paulo: Ícone, 2010.

BLOISE, G.L.F.; CARVALHO JÚNIOR, O.A.; REATTO, A.; GUIMARÃES, R.F.; MARTINS, E.S.; CARVALHO, A.P.F. Avaliação da suscetibilidade natural à erosão dos solos da bacia do Olaria-DF. Planaltina: Embrapa Cerrados. 2001.

CABRAL, J.B.P. et al. Estudo da erosividade e espacialização dos dados com técnicas de geoprocessamento na carta topográfica de Morrinhos-Goiás/Brasil para o período de 1971 a 2000. GeoFocus (Artículos), n. 5, p. 1-18, 2005.

CARMO, Danilo A.B.; VAL, B.H.P. Classificação dos Neossolos e Nitossolos quanto à natureza física, química e morfológica. FAZU em Revista, Uberaba, n. 10, p. 17-26, 2013.

CARVALHO, Morel de P. E. et al. Correlação entre o índice de erosividade EI30 médio mensal e o coeficiente de chuva do município de Mococa, SP. Científica - Revista de Agronomia, n. 19, p. 1-7, 1991.

CARVALHO, Newton de O. Hidrossedimentologia prática. Rio de Janeiro: Companhia de Pesquisa em Recursos minerais (CPRM), 1994, 372 p.

CHAVES, T.A.; GOMES, R.A.T.; MARTINS, E.S.; CARVALHO JÚNIOR, O.A.C.; BRAGA, A.R.S.; GUIMARÃES, R.F. Mapa de erodibilidade dos solos da bacia do rio Jardim-DF. Espaço \& Geografia, v. 13, n. 2, p. 253-276, 2010.

COLODRO, G.; CARVAlHO, M. P.; ROQUE, C. G.; PRADO, R. M. Erosividade da chuva: distribuição e correlação com a precipitação pluviométrica de Teodoro Sampaio (SP). Revista Brasileira de Ciências do Solo. n. 26, p. 809-818, 2002.

CPRM - Serviço Geológico do Brasil. Atlas Pluviométrico do Brasil. Disponível em http://www.cprm.gov.br. Acesso em 05 de fevereiro de 2015.

CREPANI, Edison. et al. Sensoriamento remoto e geoprocessamento aplicados ao zoneamento ecológico-econômico e ao ordenamento territorial. São José dos Campos: SAE/INPE, 2001. 124 p. 
CREPANI, Edison; MEDEIROS, José S.; PALMEIRA, Alessandro. F. Intensidade pluviométrica: uma maneira de tratar dados pluviométricos para análise da vulnerabilidade de paisagens à perda de solo. São José dos Campos: INPE, 2004. 92 p.

DEDECEK, Renato A. Fatores de erosividade da chuva, enxurrada e perdas de solo sob condições de Cerrado. Pesquisa Agropecuária Brasileira, n. 23, v. 12, p. 1431-1438, 1988.

FERREIRA, L. et al. Tipos de dispersantes, formas de agitação e suas relações com a erodibilidade de solos com altos teores de óxidos de ferro. Ciência e Agrotecnologia, v. 26, n. 2, p. 342-353, 2002.

FERREIRA, M.M.; FERNANDES, B.; CURI, N. Influência da mineralogia da fração argila nas propriedades físicas de Latossolos da região sudoeste do Brasil. Revista Brasileira de Ciência do Solo, v. 23, p. 515-524, 1999.

FOSTER, G. R.; McCOOL, D. K.; RENARD, K. G.; MOLDENHAUER, W. C. Conversion of the universal soil loss equation to SI units. Journal of Soil and Water Conservation, Ankeny, v. 36, n. 6, p. 355-359, 1981.

FOURNIER, F. Climat et erosion. Paris, Press Universitaries de France, 1960. 201p.

GALDINO, S. Distribuição espacial da erosividade da chuva no Estado de Goiás e no Distrito Federal. Campinas: Embrapa Monitoramento por Satélite, 2015.

GUERRA, A.J.T. O início do processo erosivo. In: GUERRA, A. J. T.; SILVA, A. S.; BOTELHO, R. G. M. Erosão e Conservação dos Solos. 8 ed. Rio de Janeiro: Bertrand Brasil, 2012.

KOUSKY, V. E. Pentad outgoing longwave radiation climatology for the South American sector. Revista Brasileira de Meteorologia, 3, p. 217-231, 1988.

LOMBARDI NETO, F.; MOLDENHAUER, W.C. Erosividade da chuva - sua distribuição e relação com as perdas de solo em Campinas (SP). Bragantia, n. 51 (2) , p. 189-196, 1992.

MACHADO, Daniel O. et al. Erosividade da chuva para o bioma Pantanal. Engenharia Sanitária e Ambiental [online], vol.19, n.2, p. 195-201, 2014.

MARQUES, João J.G.S.M.; ALVARENGA, Ramon C.; CURI, Nilton. Erosividade das chuvas da região de Sete Lagoas, MG. Pesquisa Agropecuária Brasileira, v.33, p.761$768,1998$.

MELLO, Carlos R. et al. Erosividade mensal e anual da chuva no Estado de Minas Gerais. Pesquisa Agropecuária Brasileira [online], vol.42, n.4, p. 537-545, 2007.

MICROSOFT. Planilha eletrônica EXCEL. 2010. 
NIMER, E. Climatologia do Brasil. Rio de Janeiro: IBGE, 1979. 422p.

OLIVEIRA, Luiz F.C.; ANTONINI, J.C.; GRIEBELER, N.O. Métodos de estimativa de precipitação máxima para o Estado de Goiás. Revista Brasileira de Engenharia Agrícola e Ambiental, v.12, n.6, p.620-625, 2008.

OLIVEIRA, P.T.S.; WENDLAND, E.; NEARING, M. A. Rainfall erosivity in Brazil: A review. Catena, n.100, p. 139-147, 2012.

ROQUE, C.G.; CARVALHO, M.P.; PRADO, R.M. Rainfall erosivity factor at Piraju (SP), Brazil: distribution, probability of occurrence, return period and correlation with rainfall coefficient. Revista Brasileira de Ciência do Solo, n. 25, p. 147-156, 2001.

RUFINO, R. L.; BISCAIA, R. C. M.; MERTEN, Gustavo H. Determinação do potencial erosivo da chuva do estado do Paraná através da pluviometria: terceira aproximação. Revista Brasileira de Ciência do Solo, n. 17, p. 439-444, 1993.

SALOMÃO, Fernando X.T. Controle e prevenção dos processos erosivos. In: GUERRA, Antônio T. et al. Erosão e conservação dos solos: conceitos, temas e aplicações. Rio de Janeiro: Editora Bertrand do Brasil, Cap. 7, 2007.

SALOMÃO, Fernando X.T.; CANIL, Kátia; RODRIGUES, Samantha P. Exemplo de aplicação da geologia de engenharia no controle preventivo e corretivo dos processos erosivos. Revista Brasileira de Geologia de Engenharia e Ambiental. V. 2, n. 2, p. 39-56, 2012.

SCOPEL, Iraci; SILVA, Márcio R. Erodibilidade no estado de Goiás. Uniciência, Anápolis, v. 8, n.1 e 2, p. 123-132, 2001.

SERRA, A.; RATISBONNA, L. As massas de ar na América do Sul $-1^{\text {a }}$ parte. Revista Geográfica. Rio de Janeiro: Instituto Pan-americano de Geografia e História, n. 51, p. 67-129, 1959.

SILVA, A.M. Rainfall erosivity map for Brazil. Catena, 57, 251-259, 2004.

SILVA, A.M.; ALVARES, C.A. Levantamento de informações e estruturação de um banco de dados sobre a erodibilidade de classes de solos no estado de São Paulo. São Paulo, UNESP, Geociências, v. 24, n.1, p.: 33-41, 2005.

SILVA, J. R. C.; DIAS, A. S. A erosividade das chuvas em fortaleza (CE). II Correlação com o coeficiente de chuva e atualização do fator R no período de 1962 a 2000. Revista Brasileira de Ciências do Solo. n. 27, p. 347-354, 2003.

SILVA, Marx L.N. et al. Proposição de modelos para estimativa da erodibilidade de latossolos brasileiros. Pesquisa Agropecuária Brasileira, v.34, n.12, p.2287-2298, 1999. 
SILVA, Marx L.N. et al. Índice de erosividade das chuvas da região de Goiânia, GO. Pesquisa Agropecuária Brasileira. v. 32, n. 10, p. 977-985, 1997.

SILVA, R. B.; IORI P.; SILVA, F. A. M. Proposição e validações de equações para estimativa da erosividade de dois municípios do estado de São Paulo. Irriga, v. 14, n. 4, p. $533-547,2009$

SILVA, Valtervides C. Estimativa da erosão atual da bacia do rio Paracatu (MG/GO/DF). Pesquisa Agropecuária Tropical, n. 34, v. 3. p. 147-159, 2004.

VIOLA, Marcelo R. et al. Distribuição e potencial erosivo das chuvas no Estado do Tocantins. Pesquisa Agropecuária Brasileira, v. 49, n.2, p. 125-135, 2014.

WISCHMEIER, W.H.; SMITH, D.D. Predicting rainfall erosion losses - A guide to conservation planning. Washington, USDA, 58p, 1978.

Diego Tarley Ferreira Nascimento

Doutor, mestre e graduado em Geografia pela Universidade Federal de Goiás. Atualmente é professor efetivo na Universidade Estadual de Goiás - Campus Iporá e na Pontifícia Universidade Católica de Goiás.

UEG: R. Serra dos Den, 340 - Boa Vista, Iporá - GO, 76200-000. PUC: Av. Universitária, 1440 - Setor Leste Universitário, Goiânia - GO, 74605-010.

E-mail: diego.tarley@gmail.com

Patrícia de Araújo Romão

Doutora e mestre em Geotecnia pela Universidade de Brasília e graduada em Geologia também pela Universidade de Brasília. Atualmente é professora na Universidade Federal de Goiás.

Avenida Esperança s/n, Campus Samambaia, Goiânia - GO, 74690-900.

E-mail: patricia_romao@ufg.br

\section{Maurício Martines Sales}

Doutor em Geotecnia pela Universidade de Brasília, mestre em Engenharia Civil pela Pontifícia Universidade Católica do Rio de Janeiro e Graduado em Engenharia Civil pela Universidade Federal de Goiás. Atualmente é professor efetivo na Universidade Federal de Goiás e também atua no Programa de Pós-Graduação em Geotecnia, Estruturas e Construção Civil.

Praça Universitária, s/n - Setor Leste Universitário, Goiânia - GO, 74605-220.

E-mail: sales.mauricio@gmail.com

Recebido para publicação em dezembro de 2016 Aprovado para publicação em março de 2017 